\title{
Cumulative risk factors for adolescent alcohol misuse and its perceived consequences among 16 to 20 year old adolescents in Switzerland
}

\author{
THESE
}

préparée sous la direction du Professeur Pierre-André MICHAUD

et présentée à la Faculté de biologie et de médecine de l'Université de Lausanne pour l'obtention du grade de

DOCTEUR EN MEDECINE

par

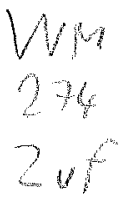

Agnès ZUFFEREY CRIPPA

Médecin diplômée de la Confédération Suisse $1347 \% 3476$

Originaire de Saint-Luc (Valais)

Lausanne 


\section{Rapport de synthèse}

OBJECTIF: évaluer 1'impact cumulatif des facteurs individuels et environnementaux associés au mésusage d'alcool chez les adolescents et leurs corrélations avec ses conséquences perçues.

METHODE : enquête scolaire transversale d'un échantillon représentatif de la population nationale, incluant 7548 apprentis et élèves ayant terminé l'école obligatoire âgés de 16 à 20 ans, en Suisse, en 2002. Le mésusage de l'alcool est fondé sur les réponses aux questions portant sur la fréquence 1) de sa consommation, 2) des épisodes d'ivresse et 3) de la conduite d'un véhicule sous son emprise.

RESULTATS : quinze facteurs de risque significatifs ont été identifiés pour les adolescents des deux sexes. Un score individuel de facteurs de risques cumulés a été calculé en les additionnant. L'association entre ce score et la probabilité d'être engagé dans le mésusage d'alcool s'est révélée hautement significative et dose dépendante $(\mathrm{p}<0.001)$. Une proportion importante des adolescents rapporte des conséquences subjectives néfastes liées à leur consommation d'alcool. Il existe une corrélation linéaire $(\mathrm{p}<0.001)$ entre le score de facteurs de risque et la proportion d'adolescents rapportant des problèmes liés à la consommation d'alcool tels que mauvaises performances scolaires, comportements à risque, problèmes relationnels et comportements sexuels à risques.

CONCLUSION : les facteurs de risque du mésusage d'alcool chez les adolescents sont cumulatifs et peuvent être synthétisés par un score individuel corrélé à la tendance à ce mésusage. La relation linéaire de ce score avec des problèmes subjectifs consécutifs à ce mésusage est un indicateur supplémentaire de sa validité. 


\title{
Cumulative risk factors for adolescent alcohol misuse and its perceived consequences among 16 to 20 year old adolescents in Switzerland ${ }^{\text {th }}$
}

\author{
Agnes Zufferey, Pierre-André Michaud*, André Jeannin, André Berchtold, \\ Isabelle Chossis ${ }^{\dagger}$, Guy van Melle, Joan Carles Suris \\ Groupe de recherche sur la santé des adolescents et Unité multidisciplinaire de santé des adolescents, \\ Institut universitaire de médecine sociale \& préventive, Lausanne, Switzerland
}

Available online 13 May 2007

\begin{abstract}
Aims. To assess the cumulative impact of environmental and individual factors associated with adolescent alcohol misuse and their correlation with self-reported consequences of drinking.

Method. Cross-sectional school-based survey of a nationally representative sample of 7548 post-mandatory school students and apprentices aged 16-20 years, Switzerland 2002. Alcohol misuse defined by frequency of alcohol use, episodes of drunkenness and driving while drunk.

Results. Fifteen significant risk factors were identified among both boys, and girls. An individual score of cumulated risk factors was created by adding the risk factors. The association between the score and the likelihood of being engaged in alcohol misuse was highly significant and dose-dependent $(p<.001)$. A significant proportion of adolescents report perceived adverse consequences of their alcohol consumption. A linear trend $(p<.001)$ was found between the score of risk factors and the proportion of respondents reporting problems related to drinking such as diminished school performance, physical hazard, relational problems and current risky sexual behavior.

Conclusion. Risk factors for adolescent alcohol misuse are cumulative and can be synthesized into an individual score correlated with the likeliness of misuse. A further indication of the validity of this score is its linear relationship with self-reported problems related to drinking. (C) 2007 Elsevier Inc. All rights reserved.
\end{abstract}

Keywords: Adolescents; Alcohol; Misuse; Consequences; Determinants; Survey

\section{Introduction}

In most industrialized countries, including Switzerland, alcohol remains by far the most popular psycho-active substance used by young people (Smart and Ogborne, 2000). Moreover, an increase in binge drinking (having consumed five or more alcoholic drinks in a row) has been demonstrated across a large number of countries (Currie et al., 2004, Hibell et al., 2000, Settertobulte et al, 2001). Alcohol misuse during adolescence has potential short- and long-term harmful

\footnotetext{
it This survey was carried out with the financial support of the Swiss Federal Office of Public Health (contract 00.001721/2.24.02.-81) and the participating cantons.

* Corresponding author. GRSA/IUMSP, Bugnon 17, 1005 Lausanne, Switzerland. Fax: +4141213143769

E-mail address: Pierre-Andre.Michaud@chuv.ch (P.-A. Michaud).

$\dagger$ Deceased.
}

consequences, such as injuries and STI's (Bonomo et al, 2001, Thompson et al, 2005), alcohol dependence (Gruber et al., 1996), behavioral problems(Wechsler et al., 1994) as well as health compromising behavior (Oesterle et al, 2004). It is therefore central to distinguish between occasional recreational use of alcohol by teenagers and potentially harmful consumption, usually referred to as alcohol misuse.

There is no universally accepted definition of alcohol misuse (Hays and Ellickson, 1996, Murgraft et al., 1999), but most authors usually agree on the fact that it can be based on two types of criteria, which are: (1) high consumption (quantity and frequency), (2) high-risk drinking (binge drinking, driving after drinking, using alcohol with other psycho-active substances). Some authors include in their definition the presence of alcohol-related problems (academic, social, physical, personal or legal adverse consequences (Ellickson et al., 1996, Windle, 1996)). The lack of consensus surrounding this definition reflects the difficulties in delineating the boundaries 
Table 1a

Criteria for the classification of drinking patterns in four categories

\begin{tabular}{|c|c|c|c|c|c|c|c|c|}
\hline \multirow{2}{*}{$\frac{\text { Alcohol consumption }}{\text { Drunkenness }^{\mathrm{a}}}$} & & \multirow[t]{2}{*}{ Never } & \multicolumn{2}{|c|}{ From timer to time } & \multicolumn{2}{|l|}{ Once a week } & \multirow{2}{*}{$\begin{array}{l}\text { More than } \\
\text { once a week }\end{array}$} & \multirow{2}{*}{$\begin{array}{l}\text { More than } \\
\text { once a day }\end{array}$} \\
\hline & & & Twice or less & 3 times or more & Twice or less & 3 times or more & & \\
\hline $\begin{array}{l}\text { Driving any motor } \\
\text { vehicle while drunk }\end{array}$ & $\begin{array}{l}3 \text { times or more } \\
\text { Twice or less }\end{array}$ & Abstinent ${ }^{b}$ & $\begin{array}{l}\text { Moderate } \\
\text { Regular }\end{array}$ & $\begin{array}{l}\text { Regular } \\
\text { Problem }\end{array}$ & $\begin{array}{l}\text { Moderate } \\
\text { Problem }\end{array}$ & $\begin{array}{l}\text { Regular } \\
\text { Problem }\end{array}$ & $\begin{array}{l}\text { Regular } \\
\text { Problem }\end{array}$ & Problem \\
\hline
\end{tabular}

"In the pervious 12 months.

b Never drank any alcohol nor drunk. Any time nor having driven while drunk.

of hazardous consumption during adolescence, a period of exploratory behaviors such as seeking drunkenness which are customary and often transitory. Thus, a definition of misuse using multiple indicators is considered the best approach (Ellickson et al., 1996, Lewinsohn et al., 1996, Windle, 1996).

Several authors in the US have identified both protective and risk factors related to alcohol use (Ellickson et al., 2001, Fergusson and Lynskey, 1996, Colder and Chassin, 1999, Lewinsohn et al., 1996, Windle, 1996, Petridou et al., 1997). However, with one exception to our knowledge (Wechsler et al., 1998), their cumulative impact has been rarely assessed. Moreover, relatively few studies have included a national representative sample of young people aged 16 to 20 years.

Also, while several longitudinal studies have focused on the short and long-term consequences of alcohol misuse by adolescents (Wechsler et al., 1994, Oesterle et al., 2004, Schulenberg and Maggs, 2002, Windle and Windle, 2005, Bates and Labouvie, 1997), very few have reported on the perceived self-reported consequences of alcohol misuse ${ }^{1}$ by adolescents. As brief interventions directed at alcohol misusers (Baer et al, 2001, McCambridge et al., 2003, Spirito et al., 2004) rely heavily on the subject's own perception of his situation and the perceived consequences of his consumption, it is important to know to what extent young people who engage in alcohol misuse properly identify such potentially harmful short-term effects.

Using a typology of patterns of drinking within a large national survey on the health and lifestyles of adolescents, this paper addresses two research questions: (1) Do socio-economic, environmental and individual risk factors have a cumulative impact on alcohol misuse? (2) What are the consequences of alcohol drinking as perceived by the adolescents and do they correlate with the extent of misuse?

\section{Methods}

The 2002 Swiss Multicenter Adolescent Survey on Health (SMASH02) is a cross-sectional study conducted in 2002 among a nationally representative sample $(n=7548)$ of post-mandatory school students and apprentices aged 16 to 20 years, which represent respectively 30 and $60 \%$ of the population of this age. 2 Apprentices are young people who work part-time in various factories and firms

\footnotetext{
${ }^{1}$ In the rest of the paper, the terms misuse and misusers will always refer to alcohol misuse and alcohol misusers.

${ }^{2}$ Ten percent of the population between 16 and 20 years are not involved in any formal/official training activity and have not been included in the sampling.
}

and part time in professional schools. All public educational institutions were included in a two stage cluster sampling, using a random cluster sample of classes which was drawn without replacement, the classes being considered as primary sampling units. From the 586 classes $(97.7 \%$ of the selected sample; $n=7548$ ) only 16 persons refused to participate and $4 \%$ of the questionnaires were discarded for incomplete data. The final number of adolescents included in the analyses was 7262 (3523 girls and 3739 boys; $96.2 \%$ of the original sample). A detailed description of the methods has been published elsewhere (Jeannin et al., 2005) and the questionnaire is available from the web (www.umsa.ch). The survey was approved by the ethical committee of the Faculty of Medicine of the University of Lausanne.

Our classification procedure refers to a previous paper (Rodondi et al., 2000), inspired by a study of Lewinsohn (Lewinsohn et al, 1996): as shown in Table 1a, four categories of drinking patterns (abstinent, moderate, regular, problem drinkers) were defined before hand, based on the answers to three questions: (1) Frequency of any alcohol use; (2) Number of episodes of drunkenness in the previous 12 months; and (3) Frequency of having driven a motor vehicle while intoxicated in the previous 12 months. Among boys, misusers were defined as those entering the category of problem drinkers $(n=972)$. As alcohol misuse was much less prevalent among girls, we have used less stringent criteria, that is, both problem and regular drinkers were considered as misusers $(n=951)$.

As the SMASH survey does not originally address substance use, we based the selection of risk factors on available data, using the literature review (Norman, 1995, Ellickson et al., 2001, Fergusson and Lynskey, 1996, Colder and Chassin, 1999, Lewinsoln et al., 1996, Windle, 1996) as a framework (Table 2). Mean scores were computed for each scale. Protective factors below the threshold were considered as risk factors. Connectedness with parents (Armsden and Greenberg, 1987) was measured using a six-item inventory (Cronbach's alpha: 85). School connectedness (Flammer et al., 1994) was assessed by a 5-item scale (Cronbach's alpha: .61). The quality of the relationship with peers, was measured with a four-item inventory (Armsden and Greenberg, 1987) tackling adolescents' perception of their peers' acceptance, trustfulness, and sensitivity to their emotional state, as well as (own) the use of their peers as confidants (Cronbach's alpha: .77). Sensation seeking was measured with a 5-item scale (Gniech et al., 1993) (Cronbach's alpha: 80). Antecedents of risky behavior included first sexual intercourse before 15 years, initiation of regular tobacco use before 14 years and first illegal drug use (including cannabis) before age 15 . Along with the hypothesis of a cumulative effect of risk factors for alcohol misuse, a scale was created which added up risk factors. As the odds ratios for the 15 significant factors (Table 2) were in the same range of values (for either girls or boys), we attributed an equal weight to all of them and a cunnulative individual score could be established in which one point was attributed for each risk factor. The maximal score among girls included 6 or more risk factors. The highest score among boys included 8 or more risk factors.

Respondents were asked whether they felt they had ever faced various consequences of alcohol drinking in four areas, using a yes/no type of answer: (1) failure to fulfill major role obligations: diminished school performance (included missing school or work), (2) physical hazard (accident, injury, quarrel or fight), (3) relational problems (with friends or parents, teachers or colleagues) and (4) sexual risk (unwanted or unprotected sexual intercourse). The first three areas of lifetime consequences alcohol drinking were derived from the DSM-IV criteria for substance abuse(American Psychiatric Association, 1994). Association between each problem and the scale score of risk factors was ascertain by regressing (logistic regression) it on the score variable. 
Table $1 \mathrm{~b}$

Prevalence of drinking patterns, by gender, Switzerland 2002

\begin{tabular}{lllr}
\hline & Abstinent $(n=497)$ & Moderate $(n=3545)$ & Regular $(n=2028)$ \\
\hline Girls $(n=3523)$ & $9.1[7.2-11.4]$ & $63.8[61.8-65.8]$ & $21.0[18.7-23.6]$ \\
Boys $(n=3739)$ & $6.3[5.3-7.4]$ & $34.6[31.9-37.4]$ & $6.1[5.1-7.2]$ \\
Total $(n=7262)$ & $7.6[6.5-8.8]$ & $48.1[46.1-50.1]$ & $26.2[23.8-28.7]$ \\
\hline
\end{tabular}

Prevalence is given as percentage [ $95 \%$ confidence interval].

All analyses were conducted with Stata 9 (Stata Corporation, 2005), allowing the calculation of coefficient estimates taking into account the sampling weights, clustering and stratification procedure. Logistic regressions were used to assess risk factors for alcohol misuse. Results are presented as adjusted odds ratios (aOR) with their $95 \%$ confidence intervals (CI).

\section{Results}

The observed proportion of patterns of drinking by gender is represented in Table $1 \mathrm{~b}$. Four hundred ninety-seven adolescents were classified as abstinents, 3545 as moderate drinkers, 2028 as regular drinkers and 1192 as problem drinkers. Table 2 provides the results of the multiple logistic regression run to identify factors statistically associated with alcohol misuse. Fifteen significant risk factors were identified among both boys and girls. For both genders, low connectedness with parents and school appeared as a risk factor for alcohol misuse. Also, antecedents of early risktaking behavior (early sexual experience/use of legal and illegal substances) appeared as a risk factor for both genders.

\section{Risk factors for alcohol misuse}

As shown in Fig. 1, both among girls and boys, the score reflecting the accumulation of risk factors correlated strongly with the risk for engaging in alcohol misuse, in a dosedependent way. The observed proportion of girl misusers increased continuously, starting at $8.6 \%$ for 0 risk factors, and reaching $80.4 \%$ for girls with a score of 6 risk factors. Among boys, the proportion of misusers rose with the score, beginning at $4.7 \%$ for a score of 2 risk factors and reaching a maximum of $58.7 \%$ for boys totaling 8 risk factors. This result confirms the strong association between cumulated risk factors and the risk of alcohol misuse (for both genders: $p<.0001$ ). As illustrated by the surface area of the spots in these figures, the majority of teenagers are concentrated between scores 1 and 3 for girls and between 3 and 6 for boys.

Table 2

Number of respondents (percents) with adjusted Odd Ratio (aOR) and $95 \%$ confidence intervals (CI) for alcohol misuse-related characteristics, by gender, Switzerland 2002

\begin{tabular}{|c|c|c|c|c|c|c|}
\hline \multirow[t]{2}{*}{ Characteristics } & \multicolumn{3}{|c|}{ Girls $(n=3523)$} & \multicolumn{3}{|c|}{ Boys $(n=3739)$} \\
\hline & $n(\%)$ & $\mathrm{aOR}^{*}$ & $95 \% \mathrm{CI}$ & $n(\%)$ & $\mathrm{aOR}$ & $95 \% \mathrm{CI}$ \\
\hline \multicolumn{7}{|l|}{ Socio-demographic factors } \\
\hline Living in rural area & $1983(57.5)$ & 0.03 & {$[0.80-1.31]$} & $2064(55.4)$ & 1.41 & {$[1.13-1.76]$} \\
\hline Swiss nationality & $3005(85.9)$ & 1.80 & {$[1.31-2.48]$} & $3132(84.4)$ & 1.61 & {$[1.20-2.16]$} \\
\hline \multicolumn{7}{|l|}{ Family-related factors } \\
\hline Parents not living together & $838(24.4)$ & 1.40 & {$[1.02-1.93]$} & $830(22.5)$ & 0.88 & {$[0.68-1.13]$} \\
\hline \multicolumn{7}{|l|}{ School-related factors } \\
\hline Frequent absenteeism ${ }^{\mathrm{c}}$ & $257(6.0)$ & 2.55 & {$[1.81-3.57]$} & $219(4.8)$ & 1.99 & {$[1.25-3.16]$} \\
\hline Low school connectedness ${ }^{d}$ & $225(4.8)$ & 1.75 & {$[1.24-2.48]$} & $320(8.0)$ & 1.80 & {$[1.29-2.50]$} \\
\hline Poor school grades ${ }^{e}$ & $86(2.2)$ & 1.85 & {$[1.07-3.19]$} & $122(3.0)$ & 1.09 & {$[0.66-1.81]$} \\
\hline \multicolumn{7}{|l|}{ Peer-related factors } \\
\hline High comectedness with friends ${ }^{f}$ & $3461(98.6)$ & 0.97 & {$[0.52-1.82]$} & $3606(96.6)$ & 1.89 & {$[1.01-3.55]$} \\
\hline Cannabis use before age 15 & $483(13.7)$ & 2.02 & {$[1.55-2.63]$} & $718(19.6)$ & 1.69 & {$[1.21-2.36]$} \\
\hline Illegal drug use before age 15 & $86(2.5)$ & 1.74 & {$[0.96-3.18]$} & $151(5.1)$ & 1.08 & {$[.055-2.13]$} \\
\hline
\end{tabular}

Confidence intervals for non-significant odds ratios are in italic.

${ }^{a}$ Mandatory school or below for both parents.

${ }^{b}$ Scale score at or below 3.0.

c Once a week or more.

¿ Scale score at or below 3.0.

"Answer "completely disagree" to item "I get good grades at school".

${ }^{f}$ Scale score above 3.0.

g Scale score at or below 2.0 . 

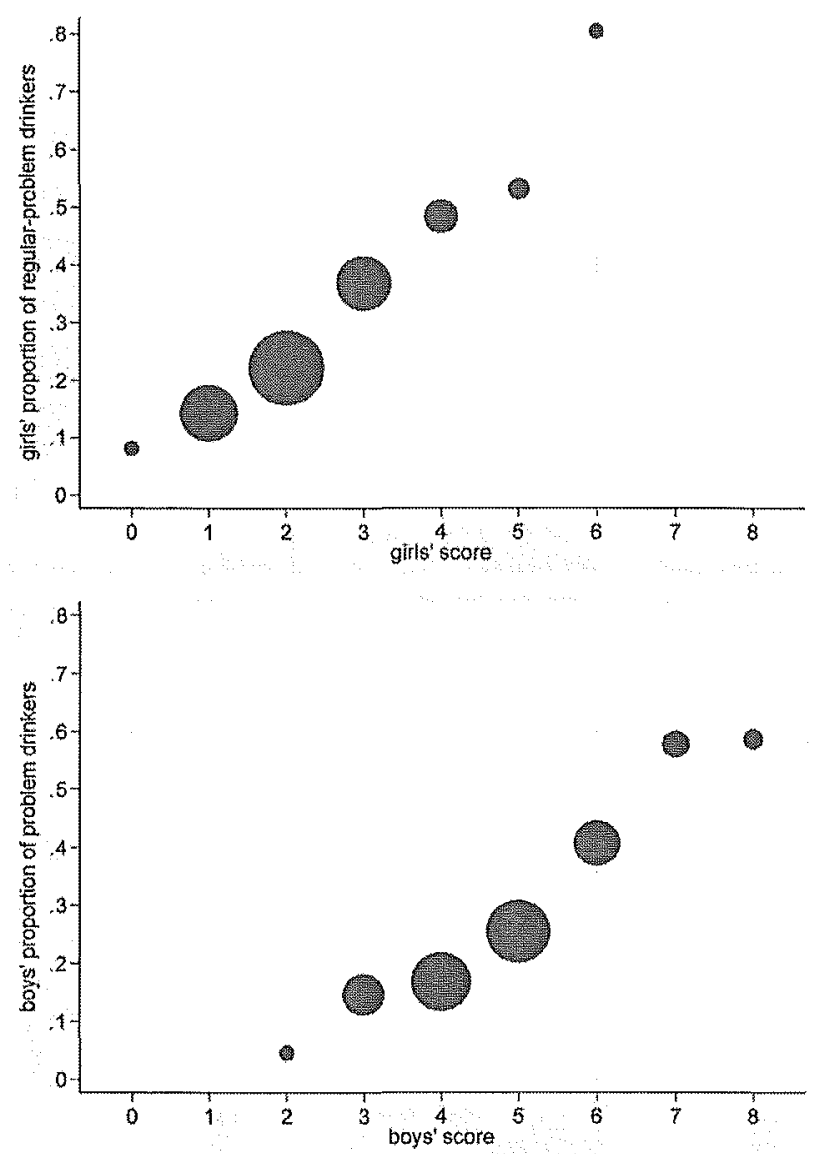

Fig. 1. Relationship between the score of risk factors and the hazard for engaging in alcohol misuse, Switzerland 2002. The surface of each point is proportional to the number of individuals with the same score (radius proportional to $/ n$ ). For both graphs, the strength of the relationship is high (girls: Pearson Design-based $F=31.4120, p<.0001$; boys: Pearson Design-based $F=31.0036, p<.0001$ ).

\section{Self-reported perceived consequences of alcohol drinking}

Tables 3 and 4 show the proportion of respondents who reported that they have faced various negative consequences of alcohol drinking. The most frequently reported problem was adverse physical consequences for boys and relational problems with friends or parents for girls. Nearly $8 \%$ of girls and $12 \%$ of boys experienced unwanted or unprotected sexual intercourse while intoxicated. The tables also show the strong association between the score of risk factors and the hazard for reporting any negative effect of drinking, with a progressive shift, as the score increases, towards more serious harmful consequences such as sexual risk or physical hazard: for instance, among those with the highest scores, nearly $30 \%$ of boys and $9 \%$ of girls reported an injury or accident due to alcohol use (data not shown on the table).

\section{Discussion}

The associations between alcohol misuse and most of the risk factors which we have included in the analyses have been described in several previous studies, particularly, the clustering of alcohol misuse with smoking and the use of illegal substances (Durant et al,, 1999, Petridou et al, 1997). Apprentices who are immersed soon after mandatory school into an adult environment and who work part-time in firms are likely to adopt adult behaviors earlier than their student counterparts (Lintonen et al., 2000). Our findings suggest that the lack of connectedness with parents is more strongly related to alcohol misuse than a broken family structure, which confirms the importance of the connectedness with parents for the mental health of adolescents (Resnick et al., 1997). Along the same line, low school connectedness was a significant risk factor for alcohol misuse: it has indeed been shown that school connectedness can be protective against harmful behaviors (Resnick et al., 1997). Connectedness with friends among boys is linked with a higher rate of alcohol misuse, while this is not the case among girls. This may be linked with the fact boys usually misuse alcohol in group more than girl do, and in this case, connectedness may not be seen as a real antecedent of alcohol misuse but rather as a co-occurring factor. But we have to recognize that this hypothesis is speculative.

While many studies tend to focus on alcohol use, this research explicitly targeted alcohol misuse. Boys are more likely to misuse than girls (Kuntsche et al., 2004), which is reflected by the fact that (Fig. 1) their score starts 2 points higher than the girls' score; in other words, among boy misusers, no one has zero risk factor, while this is the case for a few girl misusers. This study confirms that the proportion of individuals facing harmful problems such as diminished school performance, physical hazard, relational problems and current risky sexual behavior is higher among misusers than among those who abstain or drink casually. The strength of the relationship is enhanced by the cumulative, dose-dependant amount of risk

Table 3

Percents of girls reporting a problem after drinking, by score, Switzerland 2002

\begin{tabular}{|c|c|c|c|c|c|c|c|c|c|}
\hline Score value & Total & 0 & 1 & 2 & 3 & 4 & 5 & 6 & Coeff. $(\mathrm{CI})^{a}$ \\
\hline$n=$ & 3523 & 58 & 843 & 1389 & 742 & 314 & 126 & 51 & \\
\hline Diminished school performance & 3.0 & 1.4 & 1.0 & 1.7 & 3.4 & 7.7 & 13.3 & 18.2 & $.67(.53 ; .80)$ \\
\hline \multicolumn{10}{|l|}{ Relational problems } \\
\hline With friends or parents & 11.5 & 1.4 & 5.2 & 9.5 & 13.9 & 25.3 & 29.8 & 36.4 & $.51(.41 ; .62)$ \\
\hline With teachers/colleagues & 3.7 & 1.7 & 1.6 & 3.0 & 3.4 & 9.1 & 10.8 & 16.4 & $.50(.35 ; .65)$ \\
\hline Sexual risk & 7.8 & 1.4 & 2.3 & 4.8 & 12.0 & 15.1 & 30.8 & 39.7 & $.68(.57 ; .78)$ \\
\hline
\end{tabular}

Data are given as percentages. Scale range for girls is $0-6$.

${ }^{a}$ Logistic regression coefficient ( $95 \%$ confidence intervals) obtained from logistic regression of each problem on the score. 
Table 4

Percents of boys reporting a problem after drinking, by score Switzerland 2002

\begin{tabular}{|c|c|c|c|c|c|c|c|c|c|}
\hline Score value & Total & 2 & 3 & 4 & 5 & 6 & 7 & 8 & Coeff. (CI) ${ }^{a}$ \\
\hline$n=$ & 3739 & 2122 & 535 & 1048 & 1098 & 622 & 211 & 103 & \\
\hline Diminished school performance & 5.5 & 3.9 & 4.4 & 3.2 & 4.9 & 8.1 & 8.4 & 17.8 & $.32(.18 ; .46)$ \\
\hline Physical hazard & 27.6 & 20.8 & 16.1 & 17.4 & 28.3 & 38.4 & 54.2 & 63.0 & $.44(.36 ; .51)$ \\
\hline \multicolumn{10}{|l|}{ Relational problems } \\
\hline With friends or parents & 15.5 & 14.6 & 11.5 & 11.2 & 11.5 & 22.8 & 32.3 & 42.1 & $.34(.26 ; .43)$ \\
\hline With teachers/colleagues & 5.3 & 1.1 & 4.4 & 3.3 & 5.2 & 8.5 & 8.5 & 9.8 & $.29(.16 ; .40)$ \\
\hline Sexual risk & 11.7 & 8.7 & 5.4 & 8.0 & 9.1 & 15.6 & 28.4 & 51.9 & $.52(.38 ; .65)$ \\
\hline
\end{tabular}

Data are given as percentages. Scale range for boys is $2-8$.

a Logistic regression coefficient ( $95 \%$ confidence intervals) obtained from logistic regression of each problem on the score.

factors on hazard for alcohol misuse: the higher the score (the greater the number of risk factors), the greater the chance of harmful consequences of drinking. Also, as the score increases, it is not only the prevalence of problems after drinking that rises, but also the type of problems that changes. The most frequent self-reported consequence in the general girl sample is relational problems with friends or parents, whereas among girls with high scores it is sexual risk. The most frequent self-reported consequence in the general boy sample and among boys with high scores is an adverse physical outcome, but the importance of sexual risk increases proportionally, as it does among girls. We are not aware of any publication focusing explicitly on selfreported complications of alcohol use by adolescent. However, a similar inquiry has been run by Finnish colleagues and recently presented during the 2006 EUPHA meeting(Lavikainen et al., 2006): the most frequent alcohol-related consequences cited by girls was damage to property and by boys getting into scuffle. The percentages of adolescents reporting various harmful effects of alcohol drinking were quite similar to ours. Moreover, self reported alcohol-related consequences were strongly related to recurring drunkenness.

\section{Study limitations and strengths}

Some limitations of this study should be stressed. The questionnaire was filled out in the classroom, excluding absentees (rate about 5\% per day in Switzerland) and dropouts, both known to be at higher risk for substance use (Michaud et al., 1998). The proportion of problem drinkers is thus probably underestimated. In addition, the criteria employed to classify misusers are arbitrary as there is not an universally accepted definition of misuse during adolescence. However, the high degree of association which was found between alcohol misuse and the risk factor score supports the validity of this measure. We used different criteria for defining misuse among boys and girls: besides the fact that it has allowed to deal with sub samples of similar size, this decision was also based on the fact that alcohol metabolism is different among boys and girls, girls being more vulnerable to ethanol than boys(Baraona et al., 2001, Kwo et al., 1998). Another limitation of this survey is that the self-reported consequences of drinking did not refer to a specified recall period. Consequently, the simultaneity of misuse and problems after drinking could not be assessed. Finally, the cross-sectional design of the study limits the interpretation of temporal links. For instance, poor school grades can be both a cause and a consequence of alcohol misuse. This is why we have distinguished in our questionnaire and our paper risk factors such as self-reported poor grades (having repeated a year) from school problems perceived by the participants as a consequence of alcohol use. Also, school connectedness and the quality of relationship with peers may be both a cause and a consequence of alcohol misuse. There are, however, prospective studies which show the impact of such factors on further health problems (Resnick et al., 1993, 1997).

Two strengths of this paper should be raised, that is the large national representative sample of adolescents involved and the robustness of the dose-dependent correlation which we found between the score of risk factors and the proportion of subjects engaging in alcohol misuse.

\section{Conclusion}

This study brings two important findings: firstly, there is a dose-dependent relationship between the occurrence of alcohol misuse and a score cumulating a number of risk factors; secondly, adolescents identify several harmful consequences of alcohol misuse concerning themselves, the number and severity of these consequences being closely linked with the score of risk factors for alcohol misuse. These results emphasize the crucial importance of inquiring about adolescents' substance use and about their psycho-social environment. It has been recently shown that brief interventions, either in the school setting (McCambridge, 2004) or within health care structures (Spirito et al, 2004), can have some lasting effect on alcohol misuse. Given the fact that most adolescents in developed countries do see a health provider at least once a year (Jeannin et al., 2005), practitioners should take advantage of every opportunity for preventive screening and counseling, even on acute visits which constitute a large part of adolescents? consultations. Indeed, it has been recently shown that practitioners can be trained to adequately address issues such as alcohol and substance use by adolescents (McCambridge et al., 2003). The fact that a large proportion of our respondents acknowledged having experienced adverse consequences of alcohol drinking, especially those with a high score of risk factors, highlights the readiness of this segment of the population to discuss these matters. Finally, given the importance of factors such as school connectedness, this survey 
confirms the attractiveness of school health interventions which aim at improving the climate and the relationship between pupils and the teaching staff (Bond et al., 2004).

\section{Acknowledgments}

The survey was run within a multicenter multidisciplinary group from the Institute for Social \& Preventive Medicine in Lausanne*, Institute for Psychology, Psychology of Development and Developmental Disorders, University of Berne, Switzerland** and the Sezione Sanitaria, Dipartimento della sanità e della socialità, Canton Ticino***, Véronique Addor*, Françoise Alsaker**, Andrea Bütikofer**, Chantal Diserens*, Laura Inderwildi Bonivento***, André Jeannin*, Guy van Melle*, Pierre-André Michaud*, Françoise Narring**, JoanCarles Suris*, Annemarie Tschumper**.

\section{References}

American Psychiatric Association, 1994. Diagnostic and Statistical Manual of Mental Disorders. Washington.

Armsden, G., Greenberg, M., 1987. The inventory of parent and peer attachment: individual differences and their relationship to psychological well-being in adolescence. J. Youth Adolesc. 16, 427-454.

Baer, J.S., Kivlahan, D.R., Blume, A.W., Mcknight, P., Marlatt, G.A., 2001. Brief intervention for heavy-drinking college students: 4-year follow-up and natural history. Am. J. Public Health 91, 1310-1316.

Baraona, E., Abittan, C.S., Dohmen, K., et al., 2001. Gender differences in pharmacokinetics of alcohol. Alcohol., Clin. Exp. Res. 25, 502-507.

Bates, M.E., Labouvie, E.W., 1997. Adolescent risk factors and the prediction of persistent alcohol and drug use into adulthood. Alcohol, Clin. Exp. Res. 21, 944-950.

Bond, L., Patton, G., Glover, S., et al., 2004. The Gatehouse Project: can a multilevel school intervention affect emotional wellbeing and health risk behaviours? J. Epidemiol. Community Health 58, 997-1003.

Bonomo, Y., Coffey, C., Wolfe, R., Lynskey, M., Bowes, G., Patton, G., 2001. Adverse outcomes of alcolhol use in adolescents. Addiction 96, 1485-1496.

Colder, C., Chassin, L., 1999. The psychosocial characteristics of alcohol users versus problem users: data from a study of adolescents at risk. Dev. Psychopathol. 11, 321-348.

Currie, C., Roberts, C., Morgan, A., et al., 2004. Young people's health in context. Health Behaviour in School-aged Children (HBSC) study: international report from the 2001/2002 survey. Health Policy for Children and Adolescents, vol. 4. WHO Regional Office for Europe, Copenhagen.

Durant, R.H., Smith, J.A, Kreiter, S.R., Krowchuk, D.P., 1999. The relationship between early age of onset of initial substance use and engaging in multiple health risk behaviors among young adolescents. Arch. Pediatr. Adolesc. Med. 153, 286-291.

Ellickson, P., Mcguigan, K., Adams, V., Bell, R., Hays, R., 1996. Teenagers and alcohol misuse in the United States: by any definition, it's a big problem. Addiction 91, 1489-1503.

Ellickson, S.L., Tucker, J.S., Klein, D.J., Mcguigan, K.A., 2001. Prospective risk factors for alcohol misuse in late adolescence. J. Stud. Alcohol 62, 773-782.

Fergusson, D.M., Lynskey, M.T., 1996. Alcohol misuse and adolescent sexual behaviors and risk taking. Pediatrics 98, 91-96.

Flammer, A., Alsaker, F., Grob, A., 1994. Fragebogen Alltag und Schule von Kindern und Jugendlichen in der Schweiz und in Norwegen. Institut für Psychologie, Universität Bem.

Gniech, G., Oettling, T., Brohl, M., 1993. Untersuchungen zur Messung von "Sensation Seeking". Bremer Beiträge zur Psychologie. Universität Bremen, Bremen.

Greber, E., Diclemente, R.J., Anderson, M.M., Lodico, M., 1996. Early drinking onset and its association with alcohol use and problem behavior in late adolescence. Prev. Med. 25, 293--300.
Hays, R., Ellickson, P.L., 1996. What is adolescent alcohol misuse in the United States according to the experts? Alcohol Alcohol. 31, 297-303.

Hibell, B., Andersson, B., Ahlström, S., 2000. The 1999 ESPAD Report. The European School Survey Project on Alcohol and Other Drug Use among Students in 30 European Countries. The Swedish Council for Information on Alcohol and Other Drugs, Stockholm.

Jeannin, A., Narring, F., Tschumper, A., et al., 2005. Self-reported health needs and use of primary health care services by adolescents enrolled in postmandatory schools or vocational training programmes in Switzerland. Swiss Med. Wkly. 135, 11-18.

Kuntsche, E., Rehm, J., Gmel, G., 2004. Characteristics of binge drinkers in Europe. Soc. Sci. Med. 59, 113-127.

Kwo, P.Y., Ramchandani, V.A., O'connor, S., et al., 1998. Gender differences in alcohol metabolism: relationship to liver volume and effect of adjusting for body mass. Gastroenterology 115, 1552-1557.

Lavikainen, H., Lintonen, T., Metso, L., Ahlström, S., 2006. Alcohol-related negative consequences among 15 to 16 year old adolescents in Finland. Eur. J. Public Health 16 (Suppl. 1), 76.

Lewinsohn, P., Rohde, P., Seeley, J., 1996. Alcohol consumption in high school adolescents: frequency of use and dimensional structure of associated problems. Addiction 91, 375-390.

Lintonen, T., Rimpela, M., Vikat, A., Rimpela, A., 2000. The effect of societal changes on drunkenness trends in early adolescence. Health Educ. Res. 15, 261-269.

Mccambridge, J., 2004. Motivational interviewing is equivalent to more intensive treatment, superior to placebo, and will be tested more widely. Evid. Based Ment. Health 7, 52.

Mccambridge, J., Strang, J., Platts, S., Witton, J., 2003. Cannabis use and the GP: brief motivational intervention increases clinical enquiry by GPs in a pilot study. Br. J. Gen. Pract. 53, 637-639.

Michaud, P.A., DelboS-Piot, A., Narring, F., 1998. Silent dropouts in health surveys: are nonrespondent absent teenagers different from those who participate in school-based health surveys? J. Adolesc. Health 22, 326-333.

Murgraft, V., Parrott, A., Bennett, P., 1999. Risky single-occasion drinking amongst young people - definition, correlates, policy, and intervention: a broad overview of research findings. Alcohol Alcohol, 34, 3-14.

Norman, E., 1995. In: Gullotta, T., Adams, G., Montemayor, R. (Eds.), Personal Factors Related to Substance Misuse: Risk Abatement and/or Resiliency Enhancement?

Oesterle, S., Hill, K.G., Hawkins, J.D., Guo, J., Catalano, R.F, Abbott, R.D., 2004. Adolescent heavy episodic drinking trajectories and health in young adulthood. J. Stud. Alcohol 65, 204-212.

Petridou, E., Zavitsanos, X., Dessypris, N., et al., 1997. Adolescents in high-risk trajectory: clustering of risky behavior and the origins of socioeconomic health differentials. Prev. Med. 26, 215-219.

Resnick, M., Harris, L., Blum, R., 1993. The impact of caring and connectedness on adolescent health and well-being. J. Paediatr. Child Health 29, S3-S9.

Resnick, M.D., Bearman, P.S., Blum, R.W., Bauman, K.E., Haris, K.M., Jones, J.A., 1997. Protecting adolescents from harm. Findings from the National Longitudinal Study on Adolescent Health. JAMA 278, 823-832.

Rodondi, P., Narring, F., Michaud, P., 2000. Drinking behaviour among teenagers in Switzerland and correlation with lifestyles. Eur. J. Pediatr. $602-607$.

Schulenberg, J.E., Maggs, J.L., 2002. A developmental perspective on alcohol use and heavy drinking during adolescence and the transition to young adulthood. J. Stud. Alcohol, Suppl. 54-70.

Settertobulte, W., Jensen, B., Hurrelmann, K., 2001. Drinking among young Europeans. WHO European Ministerial Conference on Young People and Alcohol. World Health Organization, Stockholm.

Smart, R.G., Ogborne, A.C., 2000. Drug use and drinking among students in 36 countries. Addict. Behav. 25, 455-460.

Spirito, A., Monti, P.M., Barnett, N.P., et al., 2004. A randomized clinical trial of a brief motivational intervention for alcohol-positive adolescents treated in an emergency department. J. Pediatr. 145, 396-402.

Stata Corporation, 2005. Stata Statistical Software, Release 9.0 [computer program]. College station, TX.

Thompson, J.C., Kao, T.C., Thomas, R.J., 2005. The relationship between 
alcohol use and risk-taking sexual behaviors in a large behavioral study. Prev. Med. 41, 247-252.

Wechsler, H., Davenport, A., Dowdall, G., Moeykens, B., Castillo, S., 1994. Health and behavioral consequences of binge drinking in college. A national survey of students at 140 campuses. JAMA 272, 1672-1677.

Wechsler, H., Dowdall, G.W., Maenner, W., Gledhill-Hoyt, J., Lee, H., 1998. Changes in binge drinking and related problems among American college students between 1993 and 1997. Results of the Harvard School of Public Health College Alcohol Study. J. Am. Coll. Health 47, 57--68.

Windle, M., 1996. An alcohol involvement typology for adolescents: convergent validity and longitudinal stability. J. Stud. Alcohol 57, 627-637.

Windle, M., Windle, R.C., 2005. Alcohol consumption and its consequences among adolescents and young adults. Recent Dev. Alcohol 17, $67-83$. 